\title{
Analysis of Student's Performance Index Using Confirmatory Analysis
}

\author{
Nonong Amalita ${ }^{1}$, Dina Fitria $^{2}$, Rafi Oktriatama ${ }^{3}$ \\ \{nongmat@fmipa.unp.ac.id ${ }^{1}$, dinafitria@fmipa.unp.ac.id ${ }^{2}$ \} \\ Mathematics Department Universitas Negeri Padang, Jln Prof Dr Hamka Air Tawar Padang 1,2,3
}

\begin{abstract}
In this paper we explain student's performance index on Mathematics Department UNP. Fluctuation on student's performance index describe the academic achievement of student. Many factors contribute to this case. Based on some research, it influenced by family environment, learning motivation, college environment, and student's perception to the lecturer. So, we need a confirmatory analysis to test or confirm the measurement model which is build based on hypothesis used. The result is performance index of a student influenced by family environment, they are parents guidance, home atmosphere, economics factor on a family. Learning motivation factor include feeling happy on a lecture, interest to the topic, pay attention and student's involvement to the lecture. Campus environment factor is facilities and infrastructure on university and facilities on learning room. Student's perception factor is like and dislike factor of students to the lecturer, evaluation system chosen by lecturer, and also learning strategy of lecture.
\end{abstract}

Keywords: Analysis, confirmatory, grade point average (GPA), performance, index

\section{Introduction}

Performance index for a university students showed by grade point average (GPA). GPA is a number which is show the achievement and improvement of student's lesson. Higher the GPA of a student tells that he/she have a good academic ability.

Many factors influence the graduate point average. [1] told that external and internal factor influenced it. External factor comes from outside the student's him/herself i.e. family, school, and society. Internal factors comes from the student's him/herself, like physical and psychology. Some research about the factors which is influence the students' performance index are family condition [2], students ' interest to study [3], college society [4] and student's perception to the lecturer [5]. On explaining it factors, we need indicators. For the rest of discussion, the factors are called latent variable. Latent variable is unmeasured variable directly and needed indicator to measure it, and indicator variable is a measureable variable directly [5].

An analysis used for conform the factors influenced student's performance index is confirmatory factor analysis (CFA). General form of CFA [6] is

$$
\boldsymbol{x}=\Lambda x \xi+\boldsymbol{\delta}
$$




$$
\left[\begin{array}{c}
x_{1} \\
x_{2} \\
\vdots \\
x_{q}
\end{array}\right]=\left[\begin{array}{cccc}
\lambda_{11} & \lambda_{12} & \ldots & \lambda_{1 n} \\
\lambda_{21} & \lambda_{22} & \ldots & \lambda_{2 n} \\
\vdots & \vdots & \ddots & \vdots \\
\lambda_{q 1} & \lambda_{q 2} & \vdots & \lambda_{q n}
\end{array}\right]\left[\begin{array}{c}
\xi_{1} \\
\xi_{2} \\
\vdots \\
\xi_{n}
\end{array}\right]+\left[\begin{array}{c}
\delta_{1} \\
\delta_{2} \\
\vdots \\
\delta_{q}
\end{array}\right]
$$

Hypothesis about model on confirmatory factor analysis must be valid, which is referred to the ability of indicator to measure the object we want to be measured. Validity of an indicator is the main prerequisite for it. Validity of indicators on measure the latent variable is rated by testing whether it loading factor $\left(\lambda_{i}\right)$ is real using $t$-test for $\alpha$ level of significance. [7] a variable having good validity to a latent construct, if the value of loading factor $t$ is more than the critical value $t \geq 1.96$ or $t \geq 2$ for practice.

\subsection{Model's Goodness of Fit}

To interpret the model, whether the model is feasible or not. [5] suggest to use at least 3 goodness of fit test. Some measurement of goodness of fit to check feasibility of a model based on [7] are as follows.

\section{a. Chi-Square Test}

It test used to evaluate it fit generally and rate the measure of difference between sample and covariance matrix. The model is perfectly fit if it chi-square near zero.

\section{b. Goodness of Fit Index (GFI)}

GFI was created by Joreskog and Sorbom as alternative of chi-square and calculate proportion of variance which is note by population covariance predicted. GFI shows the accuracy of a model on creating observed covariance matrix. [7] Model is fit if GFI more than or equal to $0.9(G F I \geq 0.9)$ and it call fit marginalif $0,8 \leq G F I \leq 0,9$.

\section{c. Adjusted Goodness of Fit Index (AGFI)}

AGFI is a modification of GFI for degree of freedom (df) on a model. [7] A model is good fit if its AGFI value more than or equal to $0,9(A G F I \geq 0,9)$ and is considered fit marginalif GFI is $0,8 \leq A G F I \leq 0,9$.

\section{d. Root Mean Square Error of Approximation (RMSEA)}

RMSEA is suggestion of Steiger and Lind on 1980 and the most informative fit model indicator. RMSEA measure the deviations between parameter value of a model and its population covariance matrix. The model is good fit for $0,05 \leq R M S E A \leq 0,08$.

After doing validity test and goodness of fit for the model and reach that model is good enough, so the next step is interpret the model reach. It interpretation doing by substituting the 
value of delta $\left(\delta_{i}\right)$ and prediction value of parameter lambda $\left(\lambda_{i}\right)$ for each indicator variable into confirmatory analysis model for each latent variable.

\section{Method}

It article is an applied statistical analysis. Data used is primary data based on respond of respondent on questionnaire. Respondents are student class 2016 of Mathematics Department which are registered on academic semester July-December 2018 on FMIPA UNP. Samples are taken using proportional random sampling. Analysis data using confirmatory factor analysis.

\section{Result and Discussion}

Data is taken from students of Mathematics Department for entrance year 2016 for 157 students. Variables used are latent variable and indicator variable which we show on Table 1.

Table 1. Latent Variables and Indicator Variables.

\begin{tabular}{llc}
\hline \multicolumn{1}{c}{ Latent Variable } & \multicolumn{1}{c}{ Indicator Variable } & Symbol for Indicator Variable \\
\hline \multirow{3}{*}{ Family Environment } & Parents guidance & $X_{1}$ \\
& Residential atmosphere & $X_{2}$ \\
& Economic condition & $X_{3}$ \\
\hline \multirow{3}{*}{ Interest of Learning } & Feeling happy to the lecture & $X_{4}$ \\
& Interest to the lecture & $X_{5}$ \\
& Student's attention to the & $X_{6}$ \\
& lecture & $X_{7}$ \\
\hline \multirow{3}{*}{ University Environment } & Student's interaction in lecture & $X_{8}$ \\
& Facilities and infrastructure & $X_{9}$ \\
& Facilities on learning room & $X_{10}$ \\
\hline \multirow{3}{*}{ Perception of Students to the } & Student organization & $X_{11}$ \\
Lecturer & Favourite lecturer & $X_{12}$ \\
& Evaluation system by the & $X_{13}$ \\
\hline
\end{tabular}

We do confirmatory factor analysis using software SPSS 20 and LISREL 8.80, we reach the model of CFA which is shown in Figure 1.

Based on Figure 1, we know that the greatest loading factor $\left(\lambda_{i}\right)$ on first latent variable which is family environment for indicator residential atmosphere and the lowest loading factor is the third latent variable which is university environment for student organization indicator.

By substitute the value of delta $\left(\delta_{i}\right)$ to the prediction parameter lambda $\left(\lambda_{i}\right)$ for each indicator and latent variables into CFA model, we reach:

Model for latent variable family environment $\left(\xi_{1}\right)$ is 


$$
\mathrm{X}_{1}=0,13 \xi_{1}+0,18, \mathrm{X}_{2}=0,54 \xi_{1}+0,20, \mathrm{X}_{3}=0,37 \xi_{1}+1,11
$$

Model for latent variable interest of learning $\left(\xi_{2}\right)$ is

$$
X_{4}=0,34 \xi_{2}+0,18, X_{5}=0,40 \xi_{2}+0,13, X_{6}=0,39 \xi_{2}+0,20, X_{7}=0,43 \xi_{2}+0,35
$$

Model for latent variable university environment $\left(\xi_{3}\right)$ is

$$
X_{8}=0,46 \xi_{3}+0,31, X_{9}=0,51 \xi_{3}+0,35, X_{10}=0,11 \xi_{3}+1.13
$$

Model for latent variable perception of students to the lecturer $\left(\xi_{4}\right)$ is

$$
X_{11}=0,46 \xi_{4}+0,32, \quad X_{12}=0,38 \xi_{4}+0,42, \quad X_{13}=0,35 \xi_{4}+0,22
$$

Based on equation (2) to (5) we can conclude the greatest factor which contribute to student's GPA. Indicator to summarize which factor have the greatest contribution to GPA by checking the greatest value of lambda $(\lambda)$. It means, family environment for the case of residential atmosphere having the greatest contribution to the problem.

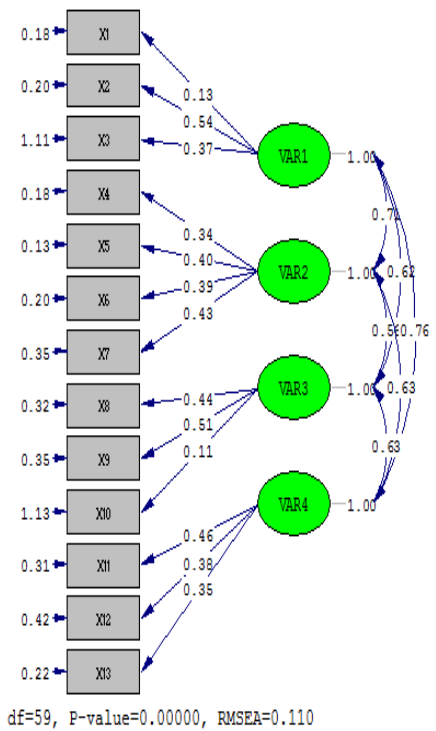

Chi-Square $=170.64, d f=59, p-$ value $=0.00000$, RMSEA $=0.110$

Fig. 1. Confirmatory Factor Analysis Model.

For the latent variable interest of learning, the greatest value of parameter lambda $(\lambda)$ is $\lambda_{7}=0.43$. It means that interest of the student to the lecture will be influence the understanding of them on how they study the lecture material. 
Latent variable university environment explained well by both indicator. The greatest value of parameter of indicator $X_{9}$ which is $\lambda_{9}=0.51$ tells us that learning facility gives students a positive thing. A good learning facilities in the university, increase the motivation of students to study.

The next, all three indicators given on latent variable student's perception to lecturer explain the latent variable well. The greatest value of parameter $(\lambda)$ in $11^{\text {th }}$ indicator for the value 0.46 . It means, the greatest indicator on explaining latent variable student's perception to the lecturer is favourite lecturer. How the lecturer loved by the students give a good feedback for students to understand the lecture material.

After finding the CFA model, we do the validity indicator. [7] a latent variable is valid on latent construct when the value of $t$ on factor loading more than the critical value of $t \geq 1.96$ or $t \geq 2$ for instant. The value of $t$ for each indicator we shows on Table 2 .

Table 2. t-value For Each Indicator Variable.

\begin{tabular}{|l|l|l|l|l|l|l|l|l|l|l|l|l|l|}
\hline & $\mathrm{X}_{1}$ & $\mathrm{X}_{2}$ & $\mathrm{X}_{3}$ & $\mathrm{X}_{4}$ & $\mathrm{X}_{5}$ & $\mathrm{X}_{6}$ & $\mathrm{X}_{7}$ & $\mathrm{X}_{8}$ & $\mathrm{X}_{9}$ & $\mathrm{X}_{10}$ & $\mathrm{X}_{11}$ & $\mathrm{X}_{12}$ & $\mathrm{X}_{13}$ \\
\hline $\mathrm{T}$ & 3,16 & 7,11 & 3,69 & 7,73 & 9,56 & 8,31 & 7,13 & 6,28 & 6,58 & 1,04 & 7,20 & 5,63 & 6,73 \\
\hline
\end{tabular}

Based on Table 2, we have an un-valid indicator on university environment variable which is joining student's organization with $t=1.04$. It indicator have to omit from the model. It means, measurement model is repaired and coefficient of weight factor is re-estimated.

\section{Goodness of Fit Model}

Goodness of fit stage is a test on checking whether a model is feasible or not. The goodness of fit of our model, can be explained by Table 3 .

Table 3. Goodness of Fit CFA Model.

\begin{tabular}{cllll}
\hline No & Index & Critical value & Result & Note \\
\hline 1 & Chi- Square & The smallest the better & 170,64 & Good enough \\
2 & GFI & $0,8 \leq$ GFI $\leq 0,9$ & 0,86 & Good \\
3 & AGFI & $0,8 \leq$ AGF I $\leq 0,9$ & 0,78 & Good enough \\
4 & RMSEA & $0,05 \leq$ RMSEA $\leq 0,08$ & 0,11 & Good enough \\
\hline
\end{tabular}

Chi-square value is 170.64 means that model cannot represent well the relation between samples or it said the model inconsistent on the real relation. GFI value 0.86 means the model is good enough. The AGFI value 0.86 means the model is good enough yet, and the RMSEA value 0.11 . RMSEA is more than 0.1 , explain that the model created cannot represent the real model searched.

The next step to reach the testing result better and fulfill general criteria for a feasible model is omitted the un-significant indicator based on the validity test. After omitted un-valid indicator from the model, the problem is re-modelled by using SPSS. 20 and LISREL 8.80. It can be seen in Figure 2.

Based on the greatest value of loading factor $\lambda$ for each latent variable, we have residential atmosphere is the indicator which explain latent variable-family environment. For latent 
variable interest of learning, it explained by student's active during lecture. Lecture facilities is loading indicator for latent variable university environment. The last, favourable lecturer is loading indicator for latent variable student's perception to the lecturer.

The next step is testing the validity of indicator based on $t$ value. The result can be found in Table 4.

Table 4. t-value for Each Indicator After Reduction.

\begin{tabular}{|l|l|l|l|l|l|l|l|l|l|l|l|l|}
\hline & $\mathrm{X}_{1}$ & $\mathrm{X}_{2}$ & $\mathrm{X}_{3}$ & $\mathrm{X}_{4}$ & $\mathrm{X}_{5}$ & $\mathrm{X}_{6}$ & $\mathrm{X}_{7}$ & $\mathrm{X}_{8}$ & $\mathrm{X}_{9}$ & $\mathrm{X}_{11}$ & $\mathrm{X}_{12}$ & $\mathrm{X}_{13}$ \\
\hline $\mathrm{t}$ & 3,16 & 7,00 & 3,68 & 7,72 & 9,56 & 8,42 & 6,95 & 6,14 & 6,43 & 7,11 & 5,66 & 6,82 \\
\hline
\end{tabular}

Based on $t$ value, we conclude that all indicator variables are valid. They valid because the $t$ value are more than 2 .

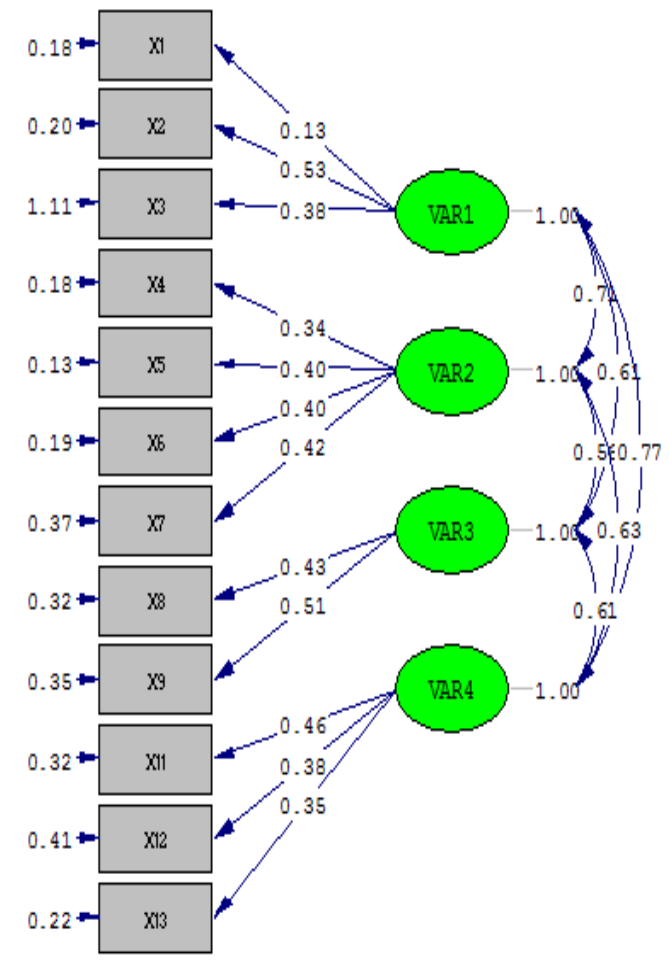

Chi-Square $=112.21, \mathrm{df}=48, \mathrm{P}$-value $=0.00000, \mathrm{RMSEA}=0.093$

Fig. 2. CFA Model After Omitted Un-Significant Indicator

After checking validity, we interpret the model, whether it feasible of not yet. Refers to the result of goodness of fit of CFA model, we reach Table 5. 
Table 5. Goodness of Fit CFA Model After Reduction.

\begin{tabular}{cllll}
\hline No & Index & Critical value & Result & Note \\
\hline 1 & Chi-square & The smaller the better & 112,21 & Good enough \\
2 & GFI & $0,8 \leq \mathrm{GFI} \leq 0,9$ & 0,89 & Good \\
3 & AGFI & $0,8 \leq \mathrm{AGFI} \leq 0,9$ & 0,83 & Good \\
4 & RMSEA & $0,05 \leq \mathrm{RMSEA} \leq 0,08$ & 0,093 & Good enough \\
\hline
\end{tabular}

Based on Table 5, we have chi-square value is 112.21. It tells that omitting un-valid indicator decrease the chi-square value for 58.43. It represent that the reduction model is given the better relation on sample into the real model. So we can say it quite consistent to explain the real condition. The GFI value 0.89 tells that model is good enough. And the value of AGFI 0.83 told that the model is not good enough yet. And the RMSEA value of 0.093 or less than 0.1 means that the model created is enough to represent the model.

\section{Conclusion}

Confirmatory factor analysis of factors influence students GPA in Mathematics Departement enterance year 2016 are as follows.

a. Family environment consist of 3 indicators, they are family guidance, residential atmosphere, economic condition. The most contributed indicator for student's GPA is residential atmosphere.

b. Interest of learning variable with 4 indicators: feeling happy to the lecture, interest to the lecture, student's attention to the lecture and student's interaction in lecture. Interest to the lecture is the dominant factor in this latent variable.

c. University environment using 2 indicators, are facilities and infrastructure and facilities on learning room. The second one is the most contributed to GPA.

d. Perception of students to the lecture, expand using three indicators, they are favourite lecturer, evaluation system by the lecturer, learning system by the lecturer and favourite lecturer is the greatest contributed factor for GPA.

\section{References}

[1] Zhang, G., Anderson, T. J., Ohland, M. W., \& Thorndyke, B. R.: Identifying factors influencing engineering student graduation: A longitudinal and cross- institutional study. Journal of Engineering education, 93(4), 313-320 (2004)

[2] Leithwood, K., \& Jantzi, D.: The relative effects of principal and teacher sources of leadership on student engagement with school. Educational administration quarterly, 35(5), 679-706 (1999)

[3] Greene, B. A., \& Miller, R. B.: Influences on achievement: Goals, perceived ability, and cognitive engagement. Contemporary Educational Psychology, 21(2), 181-192 (1996)

[4] Jayakumar, U.: Can higher education meet the needs of an increasingly diverse and global society? Campus diversity and cross-cultural workforce competencies. Harvard Educational Review, 78(4), 615-651 (2008) 
[5] Shevlin, M., Banyard, P., Davies, M., \& Griffiths, M.: The validity of student evaluation of teaching in higher education: love me, love my lectures?. Assessment \& Evaluation in Higher Education, 25(4), 397-405 (2000)

[6] K. A. Bollen. 1989. Structural Equations With Latent Variables,New York: A Wiley-Interscience Publication

[7] Sarjono, Haryadi. 2015. Structural Equation Modelling (SEM). Jakarta Selatan : Salemba Empat. 